\title{
Problemas métricos en «Lo fatal» de Rubén Darío: escansión y estructura estrófica
}

Antonio Alcoholado Feltstrom ${ }^{1}$

Resumen. Este trabajo atiende a problemas métricos característicos de "Lo fatal": anomalías de escansión y casos de encabalgamiento que desafían el modelo de verso y la relevancia acentual que se ha otorgado al axis rítmico en la tradición métrica de nuestra lengua, junto con el llamativo esquema estrófico del poema. A partir de hechos de lengua excepcionales pero naturales, observados tanto en el campo de la fonética del español como en el de su versificación, plantea un modelo de ejecución del verso 8 que reconciliaría el conflicto entre prosodia y ritmo que han observado estudios anteriores. Propone asimismo la escansión del verso 12 a partir de la lógica rítmica del poema y del uso del encabalgamiento en versos anteriores del mismo poema, a la vez que revisa su posible denominación estructural como soneto.

Palabras clave: métrica; oralidad; alejandrino; modelo de ejecución; acento; encabalgamiento.

\section{[en] Meter Issues in Ruben Dario’s “Lo fatal”: scansion and stanza structure}

\begin{abstract}
This paper focuses on problematic meter practices in the poem "Lo fatal", mainly scansion anomalies and enjambment examples that defy the Alexandrine verse design and the traditional relevance of line final stress, altogether with its unique stanza structure. It considers a delivery design of line number 8 based on observations of language facts in the study of both Spanish phonetics and meters, and suggests the scansion of line 12 according to inner rhythm in the poem and the use of enjambment in other lines of the same composition, while reviewing its possible sonnet stanza structure denomination.
\end{abstract}

Keywords: meters; orality; Alexandrine verse; delivery design; stress; enjambment.

Sumario. 1. Introducción. 2. "Lo fatal" desde el punto de vista métrico. 3. El verso alejandrino y el soneto hasta el modernismo. 4. Modelo de verso y de ejecución. 5. Correspondencias entre verso y habla. 6. "Lo fatal": versos 8 y 12. 7. Estructura estrófica. 8. Métrica y oralidad en "Lo fatal".

Cómo citar: Alcoholado Feltstrom, A. (2021) Problemas métricos en "Lo fatal” de Rubén Darío: escansión y estructura estrófica, en Anales de Literatua Hispanoamericana 50, 103-115.

\section{Introducción}

La composición que cierra Cantos de vida y esperanza ha generado concienzudos análisis como los de Amado Alonso ([1955] 1969), Anne Maria Morris (1966), Michael Predmore (1971) y Raquel Carranza Crespo (1979), que ofrecen, en conjunto, una visión completa desde los puntos de vista temático, argumentativo, sintáctico y semántico.

El que nos ocupa en estas páginas atiende exclusivamente a problemas métricos del poema, concretamente a la escansión de dos de sus versos en relación con el recurso del encabalgamiento y de la prominencia acentual como posible mimetismo de la espontaneidad oral por parte de Rubén Darío; desde el punto de vista estrófico, se discute la posibilidad de denominarlo soneto o no.

\footnotetext{
${ }^{1}$ Universitat Jaume I. España.

Email: $\underline{\text { alcohola@uji.es }}$
} 
Comenzaremos con una breve presentación del poema y sus versos problemáticos (apartado 2), para ofrecer a continuación, de manera sucinta, el desarrollo histórico del verso alejandrino y del soneto desde su empleo inicial en español hasta su uso en el modernismo (apartado 3). Acto seguido, procederemos a repasar los conceptos de modelo de verso y modelo de ejecución (apartado 4), así como las correlaciones lingüísticas entre el habla y el verso en español, con especial atención a las funciones del acento en el verso y en el grupo fónico, por un lado, y a la correlación entre el encabalgamiento y la sintaxis oral en la creación de efectos expresivos en la comunicación (apartado 5). Para todo ello, nos apoyaremos en trabajos específicos de métrica $^{2}$ y en diversas contribuciones al conocimiento del habla española ${ }^{3}$.

Nos detendremos después en los aspectos de escansión que destacan a los versos 8 y 12 del poema (apartado 6). Con respecto al verso 8, recurriremos a las funciones del acento en el enunciado oral para ofrecer una explicación a su llamativa irregularidad, recurriendo a los conceptos de modelo de verso y modelo de ejecución; en cuanto al verso 12, expondremos una interpretación métrica que no parece haberse considerado en estudios anteriores.

Discutiremos también la oportunidad de emplear la denominación de soneto para esta composición de Rubén Darío, de acuerdo con sus aspectos formales y casos de otras composiciones anteriores (apartado 7).

Para terminar, insistiremos en el reflejo de la oralidad al que parecen responder las particularidades métricas de "Lo fatal", considerando aspectos y testimonios que apoyan el planteamiento ofrecido en este estudio (apartado 8).

\section{2. "Lo fatal" desde el punto de vista métrico}

En su estudio sobre la versificación de Rubén Darío, Domínguez Caparrós (1999: 47) destaca el papel esencial del análisis métrico en la exploración de la lengua poética de Rubén Darío, dado que los metros de este poeta presentan problemas a sus estudiosos, entre los que no hay unanimidad. Enumera "Lo fatal" entre sus composiciones más revolucionarias desde el punto de vista métrico e insiste en que el análisis de las formas de versificación del poeta nicaragüense es "terreno aún fértil" tanto para la investigación como para el debate en nuestros días, así como para seguir indagando en las relaciones entre métrica y expresión (Domínguez Caparrós, 1999: 60, 62, 65). En este trabajo partimos de estas afirmaciones en la aproximación a problemas que aún no parecen haberse resuelto.

Aunque este trabajo se limita a una sola composición en concreto, es significativo el carácter de continuidad que esta presenta en la producción de su autor, tanto en el plano técnico de la versificación como en recurrencia de imágenes ${ }^{4}$. Sin detenernos en temas y fuentes de este poema ${ }^{5}$, procedemos a considerar sus metros.

Se acepta que los primeros once versos del poema son alejandrinos, verso recurrente en la obra de Darío, que explota sus posibilidades expresivas por influencia del ejemplo francés (Mapes, 1940: 16; Torre, 1999: 83; Utrera Molina, 2016: 227-229). Los dos últimos versos de "Lo fatal", sin embargo, no parecen a primera vista corresponderse con el esquema alejandrino.

${ }^{2}$ A lo largo de este artículo, recurrimos con frecuencia a Tomás Navarro Tomás (1944, [1956] 1974, [1959] 2004b) y José Domínguez Caparrós (1988, 1999, 2001), entre otros trabajos como los de Rafael de Balbín (1968), Antonio Quilis (1984), Gili Gaya (1993), Esteban Torre (1999 y 2013) o Isabel Paraíso (2000).

${ }^{3}$ Como Navarro Tomás ([1918] 2004a), Alcina y Blecua (1975), Quilis (1999), Hidalgo Navarro y Pérez Giménez (2004), Hualde (2005), Gil Fernández (2007), Prieto (2007), la Real Academia Española y la Asociación de Academias de la Lengua (en adelante: RAE y ASALE, 2011), Hidalgo Navarro y Quilis Merín (2012).

${ }^{4}$ Puede encontrarse un antecedente inverso a la alusión al árbol y a la piedra en "La fuente", una pieza del conjunto Las ánforas de Epicuro, incluido en Prosas profanas: “... junto al árbol que llora y la roca que siente..." En otras dos composiciones de Cantos de vida y esperanza, Darío presenta el árbol como ente natural que participa en la comunicación poética (“... lo que el árbol desea decir y dice al viento...”, en "Ay, triste del que un día") y como representación misma del poeta ("Yo, pobre árbol, produje, al amor de la brisa...", en "De otoño").

${ }^{5}$ Amado Alonso (1969: 331-332, 334-338) le atribuye influencia de unos versos del escultor Miguel Ángel Buonarroti, mientras que Rubén Benítez (1972: 510-511) ha encontrado lazos más evidentes con un pasaje de El mundo como voluntad y representación, de Schopenhauer. Entre Alonso y Benítez, otros autores discrepan del primero y rastrean un número de fuentes posibles, como detallan el propio Benítez (1972) y Emilio Blanco (1995), quien concluye que es fácil encontrar similitudes entre este poema y un número elevado de textos, sin que pueda determinarse cuáles son fuentes directas o no (Blanco, 1995: 153). 
Reproducimos a continuación el poema ${ }^{6}$, marcando la pausa entre hemistiquios con una barra vertical (|) y numerando los versos pertinentes para nuestro estudio, en cuyos casos particulares nos detendremos más tarde:

Dichoso el árbol que es | apenas sensitivo y más la piedra dura | porque esa ya no siente, pues no hay dolor más grande | que el dolor de ser vivo, ni mayor pesadumbre | que la vida consciente.

Ser y no saber nada $\mid$ y ser sin rumbo cierto, y el temor de haber sido $\mid \mathrm{y}$ un futuro terror... Y el espanto seguro | de estar mañana muerto, y sufrir por la vida | y por la sombra y por

lo que no conocemos $\mid \mathrm{y}$ apenas sospechamos, y la carne que tienta $\mid$ con sus frescos racimos, y la tumba que aguarda $\mid$ con sus fúnebres ramos, 12 ¡y no saber adónde vamos ni de dónde venimos...!

De entrada, el lector se halla con dos problemas métricos llamativos: en primer lugar, el abrupto final de verso y estrofa que tiene lugar en el verso 8, final marcado por encabalgamiento con la estrofa siguiente y por la ubicación de una partícula átona, la preposición por, en posición de axis rítmico o acento final de verso (Balbín, 1968: 41-42), que convencionalmente corresponde a palabras tónicas; en segundo lugar, la cantidad silábica del verso 12 , que con sus nueve sílabas métricas no se ajusta al molde alejandrino de hemistiquios heptasílabos. El verso 13, aunque visiblemente reducido, es heptasílabo y por tanto se ajusta a dicho esquema; encontramos, además, en otras composiciones anteriores ${ }^{7}$ de Rubén Darío, la presencia de versos simples, equivalentes a hemistiquios del verso compuesto empleado mayoritariamente, a modo de pie quebrado en determinadas estrofas o, sencillamente, alternados entre otros versos compuestos.

También, la disposición gráfica del poema recuerda la de un soneto, si bien es evidente a la vista la ruptura formal con la convención de dicha combinación estrófica.

\section{El verso alejandrino y el soneto hasta el modernismo}

El alejandrino es un verso compuesto por dos hemistiquios heptasílabos $(7+7)$ entre los que media una pausa interior que, al igual que la pausa final de verso, impide la sinalefa y equipara el cómputo silábico a partir del último acento del primer hemistiquio, en la sexta sílaba, igualando final oxítono, paroxítono y proparoxítono (Navarro Tomás, 1974: 85; Balbín, 1968: 175-176; Quilis, 1984: 33 y 80; Domínguez Caparrós, 2001: 30). Esta pausa entre hemistiquios ${ }^{8}$ es un rasgo característico del verso alejandrino que necesitamos tener en cuenta en el análisis de versos de "Lo fatal" que realizaremos en la sección 6.

El alejandrino se empezó a emplear en la versificación castellana en el siglo XIII, a través de la traducción del Libro de Alexandre en el Estudio General de Palencia (Uría, 1986: 14), y se instituyó como verso distintivo del mester de clerecía (Torre, 1999: 79), dado su carácter narrativo y didáctico (Rico, 1985: 4). A partir del siglo XV su uso declina para resurgir en el XVIII y recuperar relevancia en el romanticismo (Torre, 1999: 79-81; Alatorre, 2012: 368-385).

A raíz de las innovaciones practicadas por autores franceses, introducidas por Sinibaldo de Mas en la versificación española, que habían modificado la correspondencia tradicional entre sintaxis y hemistiquios, el verso alejandrino experimenta un cultivo intenso en nuestras letras en el modernismo (Navarro Tomás, 1974: 419-420; Alatorre, 2012: 386-390).

\footnotetext{
${ }^{6}$ Lo mostramos tal como está reproducido en el sitio web de la Real Academia Española, donde refieren como fuente la antología elaborada por Guillermo de Torre (1966).

7 “Año nuevo" y "Palimpsesto" en Prosas profanas, "Melancolía" y "Letanía de nuestro señor don Quijote" en Cantos de vida y esperanza.

${ }^{8}$ Quilis (1984: 75 y 80) identifica esta pausa entre hemistiquios con el concepto de cesura; por el contrario, Navarro Tomás (1974: 40), Balbín (1968: 168, 173 y 176-177) y Domínguez Caparrós (2001: 70 y 257) diferencian la pausa interna, característica de los versos compuestos, de la cesura, que de acuerdo con sus explicaciones no separa hemistiquios sino que solo constituye un reposo en la entonación.
} 
A juicio de Navarro Tomás, estas innovaciones en el verso alejandrino rompen los límites de la correspondencia gramatical entre verso y unidad sintáctica, al igual que la disciplina del acento, al aplicar diversos mecanismos de encabalgamiento entre hemistiquios y entre versos que no alteran la estructura métrica pero violentan la fonética del español al colocar palabras átonas en posiciones de acento prosódico (Navarro Tomás, 1974: 420-423, 467, 570), lo que plantea una discrepancia entre la forma del verso y la posible comprensión lingüística del mensaje.

Por lo que respecta al soneto, su cultivo en castellano lo inició el Marqués de Santillana en el siglo XV, con una estructura de rimas variable en las dos primeras estrofas $\left(\mathrm{ABAB} A B A B{ }^{9}, \mathrm{ABAB} B C C B, A B B A\right.$ ACCA...) que se sigue practicando en el Siglo de Oro, en el que también se experimenta, aunque de manera escasa, el ejercicio de esta combinación estrófica con versos octosílabos y alejandrinos en lugar de endecasílabos (Navarro Tomás, 1974: 155-156, 252, 270, 277). Un amplio catálogo de variaciones formales del soneto se halla en Arte poética española de Juan Díaz Rengifo ([1606] 2007), cuyos detalles resume Domínguez Caparrós (2001: 410-415, 419-421). También Juan Caramuel ([1665] 2007: 351-363) registra múltiples estructuras de rima y cantidades silábicas en el soneto.

No es hasta el neoclasicismo que se fija la estructura de rima en los cuartetos (ABBA ABBA), mientras que los tercetos mantienen su esquema variable, convención que se mantiene durante el romanticismo (Navarro Tomás, 1974: 306, 350). Sinibaldo de Mas retomó el ejercicio del soneto en verso alejandrino según los precedentes de los siglos XVI y XVII, influyendo en los modernistas (Navarro Tomás, 1974: 424).

Paralelamente al empleo extendido y revolucionario que experimenta el alejandrino, según hemos recordado en el apartado anterior, el soneto recupera durante el modernismo la libertad en combinaciones de rima y adopta una asombrosa plasticidad de metros (Navarro Tomás, 1974: 400-401).

El soneto, en lo concerniente a contenido, ha de mantener unidad temática y quedar completo en su desarrollo (Domínguez Caparrós, 2001: 408), mientras que, en lo que respecta a la forma, se da lugar en el modernismo a un amplio repertorio de metros y a la rima cruzada en los cuartetos.

Acerca del ejercicio experimental con el soneto por parte de los modernistas, es de especial relevancia para nuestro estudio el soneto de trece versos (Navarro Tomás, 1974: 432; Domínguez Caparrós, 2001: 421), así denominado por la singular composición igualmente titulada por el mismo Darío en Cantos de vida y esperanza: soneto en eneasílabos en el que queda omitido el verso 14 y se deja la composición en suspenso. A pesar de que el soneto está tradicionalmente compuesto por 14 versos, Navarro Tomás (1974: 432) refiere la existencia de un soneto de trece versos con sentido completo escrito por Calderón de la Barca; antes de Calderón, Díaz Rengifo había registrado otro tipo de soneto con distinto número de versos en el que fue, según el mismo Navarro Tomás (1974: 44), "el más famoso libro de métrica de su tiempo", el soneto doblado, con veinte versos: catorce endecasílabos y seis heptasílabos (Domínguez Caparrós, 2001: 413-414); tampoco podemos olvidar el soneto con estrambote, cuyo número de versos se extiende hasta diecisiete (Domínguez Caparrós, 2001: 416-417).

\section{Modelo de verso y de ejecución}

En relación directa con las innovaciones formales aplicadas al verso alejandrino en español por influencia francesa, tienen interés primordial en este estudio los conceptos de modelo de verso y modelo de ejecución. Domínguez Caparrós (1988: 244-245) los explica a partir de los formalistas rusos y el estructuralismo, a través de Jakobson, como lo que se espera convencionalmente de un tipo de verso determinado de acuerdo con la tradición, por un lado (modelo de verso), y como interpreta el receptor que ha de declamarse un verso concreto (ejecución).

Tras recordar el valor de los elementos lingüísticos en el estudio del verso, Jakobson (1981: 348-349, 361) destaca que la dimensión rítmica del verso hace que este fluctúe entre la música y la lengua; Torre (1999: 11-13), al hablar de estos conceptos, explica que el ritmo constituye un ejemplo del modelo de ejecución, al mismo tiempo que advierte de la imposibilidad de separar metro de significado (Torre, 1999: 20 ), antes de centrar su atención en el verso alejandrino como "paradigma" de estructura métrica en la que el

\footnotetext{
${ }^{9}$ Esta rima cruzada es la más frecuente en los sonetos del Marqués de Santillana, con una proporción del 76,1\% entre las estructuras de rima empleadas en los ocho primeros versos (Gutiérrez Carou, 1992: 135, 140).
} 
modelo de verso se enfrenta a transformaciones mediante la ejecución (Torre, 1999: 79 y siguientes), todo lo cual se ajusta al propósito particular de este estudio, como se verá más tarde.

El modelo de verso vendría a ser una abstracción en la que se representa un sistema regularizado, mientras que el modelo de ejecución se mueve entre los extremos del ritmo y de la prosa (Domínguez Caparrós, 1988: 241, 244-245). Sin embargo, Jakobson (1981: 371, 374) describe el modelo de verso más como idealización que como abstracción, idealización que representaría todos los ejemplos de verso (variedad de escansiones posibles) correspondientes a un metro determinado.

Desde la óptica de la sintaxis, las innovaciones sobre el verso alejandrino practicadas en español por Sinibaldo de Mas y los modernistas, exploradas en profundidad ejemplar por Rubén Darío, ilustran de manera idónea esta oposición entre modelo de verso, en cuanto a estructura sintáctica cabe esperar en un verso alejandrino, de acuerdo con la tradición métrica, y modelo de ejecución, entendido como la realización particular de un alejandrino concreto, que puede o bien escapar al patrón característico del verso mediante una dicción prosaica, en un extremo, o bien enajenar su contenido lingüístico a su esquema rítmico, en el otro, o tal vez mediar entre ambos extremos (Domínguez Caparrós, 1988: 241, 244-245). Recordemos en todo caso la advertencia de que el verso no puede sacrificar su significado en favor de su constitución métrica (Torre, 1999: 20).

En el caso concreto de los problemas métricos de "Lo fatal", existe evidencia fonológica que puede sustentar la idea de que Rubén Darío contaba con el valor del significado sin desdeñar la función de la forma en la escansión experimental del verso alejandrino, como expondremos en los apartados 6 y 8.

Por otro lado, cabría tal vez la posibilidad de preguntarse si se da también un determinado modelo de estrofa, o de combinación de estrofas, frente a otro de ejecución estrófica que, como sucede en el caso del verso, modifique el conjunto de sus variables formales mediante una realización expresiva concreta que pueda alejarse de la idea predeterminada que la convención haya adoptado. Volveremos sobre esta idea en el apartado 7 .

\section{Correspondencias entre verso y habla}

Hasta el siglo XX, en el que se deja de vincular la enseñanza y práctica de la pronunciación con la de la métrica (Paraíso, 2000: 21), era común que se presentase la segunda como guía para la práctica de la primera. Así Nebrija, por ejemplo, en su gramática inaugural del castellano, presenta la relación entre verso y habla en siete de los diez capítulos que dedica a la prosodia (Nebrija, [1492] 1980: 137-138; 144-160). A lo largo del siglo XIX, prosodistas como Sicilia (1832), Bello (1835) y Benot (1892) mantienen esta vinculación académica entre las dos disciplinas.

Ya en el siglo XX, a pesar de la separación entre los estudios del habla y los del verso, Navarro Tomás combina el cultivo de ambos (como también hicieron otros autores citados en este trabajo: Alarcos, Quilis y Gili Gaya) y denuncia la noción de una supuesta diferencia de pronunciación según se lean versos o se hable (Navarro Tomás, [1918] 2004a: 149), idea que sigue criticando Henríquez Ureña ([1934] 1998: 171-172) y, más avanzado el siglo, también Alarcos ([1976] 2004: 331). En nuestros días, Esteban Torre (2013: 190) sigue llamando la atención a este respecto, lo que ilustra la relación que inevitablemente mantienen la lengua oral y la versificación.

En su estudio de la métrica española, Quilis (1984: 55, 81-82) señala la correspondencia fisiológica y morfosintáctica que existe entre el verso y la concatenación de sílabas en el habla o grupo fónico: ambos quedan aislados de otros versos o de otros grupos fónicos por pausas y contienen un mensaje estructurado con la mayor coherencia posible en su contexto según pautas de comunicación.

Las definiciones de verso que encontramos en Navarro Tomás (2004b: 10) y en Domínguez Caparrós (2001: 454) señalan también la relación fisiológica entre grupo fónico y verso.

Los elementos que estructuran el verso: sílaba, acento, pausa y entonación, son también los que configuran la estructura y el significado en el habla (Balbín, 1968: 27-28; Quilis, 1984: 21), exactamente los mismos que constituyen el grupo fónico ${ }^{10}$.

Por ello, Balbín (1968: 15, 27-28) describe el discurso oral como cadena fónica que presenta dos modalidades: cadena fónica prosaria o prosa y cadena fónica rítmica o verso, pues la diferencia entre el

\footnotetext{
${ }^{10}$ Afirma Quilis (1984: 21) que los aspectos estilísticos del verso español, tales como la alteración de la sintaxis convencional de la lengua escrita mediante hipérbaton, parten también de "motivaciones en el plano del habla".
} 
verso y la prosa reside solamente en que el primero se caracteriza por contar con esquemas rítmicos intencionados, frente a la carencia de ritmo planificado del habla ordinaria (Henríquez Ureña, 1998: 156; Navarro Tomás, 1974: 35; Balbín, 1968: 28; Gili Gaya, 1993: 51; Domínguez Caparrós, 2001: 287), quedando el verso sujeto a patrones de los que el habla espontánea está exenta (Paraíso, 2000: 23).

A diferencia del grupo fónico, pues, el verso viene definido por una serie de características, como son la cantidad silábica y el ritmo acentual, que lo regulan de acuerdo a preceptos (Navarro Tomás, 2004b: 10-11; Quilis, 1984: 17 y 21-22; Domínguez Caparrós, 2001: 454-5).

Alcina y Blecua (1975: 455) observan que los grupos fónicos de mayor extensión tienden a dividirse en unidades melódicas de siete u ocho sílabas, lo que dota de regularidad tanto a la respiración como a la planificación, articulación y percepción del habla, según indica Prieto (2007: 41). Esta estructura se corresponde con la del alejandrino, verso que analizaremos en este estudio.

Procedemos a continuación a detenernos en dos aspectos determinantes en este estudio métrico: el acento, de especial relevancia en el análisis de uno de los versos que nos ocupan, y el encabalgamiento, que, según la escansión del verso 12 que proponemos, caracteriza a los dos.

Con respecto al acento como elemento constituyente tanto del grupo fónico como del verso, tiene especial relevancia para este estudio, como se verá en el análisis del verso 8 de "Lo fatal", la distinción entre diversos tipos de acento según su función prosódica. Así, se diferencia acento primario, correspondiente al acento léxico, que caracteriza a las palabras tónicas frente a las átonas, de acento secundario, menos prominente y presente también en fragmentos de discurso mayores que la palabra (Navarro Tomás, 2004a: 195-196; Quilis, 1999: 396; Torre, 1999: 36; Hualde, 2005: 243; Gil Fernández, 2007: 285-286; RAE y ASALE, 2011: 42, 356, 364-365, 369).

Torre (1999: 32, 36) explica que, en el verso español, el acento es una entidad relativa, sujeta a las circunstancias de su entorno: una sílaba tónica puede perder intensidad e incluso volverse átona, y viceversa, dependiendo de su posición en la estructura rítmica del verso, de la entonación o del énfasis dictado por el interés expresivo, siendo normal la alternancia acentual, tanto en la lengua poética como en la cotidiana.

Navarro Tomás llama al acento secundario acento rítmico, y distingue asimismo el acento activo, que efectúa su función prosódica, del acento ocioso, atenuado por la relevancia de otro acento cercano (Navarro Tomás, 2004b: 20-21).

Por otro lado, el acento sintáctico o de frase constituye el acento de mayor prominencia en un grupo fónico, normalmente correspondiente al último acento léxico del enunciado (Gil Fernández, 2007: 284; Prieto, 2007: 42; RAE y ASALE, 2011: 17, 42, 356, 423; Hidalgo Navarro y Quilis Merín, 2012: 257), mientras que el acento enfático otorga ocasionalmente, por voluntad del hablante, mayor prominencia a un componente determinado del enunciado, pudiendo esta prominencia prosódica superar a la del acento de frase (Quilis, 1999: 396; Gil Fernández, 2007: 286-287; RAE y ASALE, 2011: 42, 424-425; Hidalgo y Quilis Merín, 2012: 259-260). Navarro Tomás (2004a: 194-195) atribuye razones lógicas o emocionales a la extraordinaria prominencia de este acento, que, como veremos más adelante, podría desempeñar un papel excepcional también en el verso.

Por su parte, el acento tonal sirve de apoyo a la entonación de acuerdo con la intención expresiva del enunciado, cumpliendo una función determinante en su estructura entonativa (Hualde, 2005: 241, 243, 245; RAE y ASALE, 2011: 17, 426-428, 443).

En la versificación se tiene en cuenta el axis rítmico o acento final del verso, equivalente al acento sintáctico o final de frase, que determina la cantidad silábica del mismo, condiciona la rima, anticipa la pausa y suele, por la relevancia de su intensidad, impedir la sinalefa (Navarro Tomás, 1974: 39; Balbín, 1968: 4142, 79; Quilis, 1984: 52, 80, 91-92; Domínguez Caparrós, 2001: 50, 257), es característico del verso español y se corresponde con el acento de frase, al ser el más prominente; cumple también con la función de acento tonal (Balbín, 1968: 42; Quilis, 1984: 91; Domínguez Caparrós, 2001: 50).

Gili Gaya (1993: 44-45, 50) muestra evidencia instrumental de la elevación y descenso de tono en acentos prosódicos de verso, mostrando su relación evidente, pero también encuentra que, en determinadas circunstancias expresivas, se anula la correspondencia entre acento y anclaje del tono. Entre estas circunstancias, incluye la prominencia de "una palabra más significativa" y los casos de encabalgamiento, al que dedicamos el siguiente apartado.

En lo que respecta al otro aspecto determinante en nuestro estudio de los problemas métricos de "Lo fatal", el encabalgamiento, para entender su relación con el habla espontánea es oportuno detenerse un momento en la unidad de discurso inmediatamente inferior al grupo fónico, entre cuyas denominaciones optamos aquí por la de sirrema (Quilis, 1999: 372), combinación de palabras entre las que se establece una unidad tonal, gramatical y de sentido, por lo que no se espera pausa entre ellas (Gil Fernández, 2007: 299, 
302): por ejemplo, grupos sintagmáticos como determinante y sustantivo, preposición y el complemento que introduce, verbo y pronombre que hace de su objeto, etc.

Téngase en cuenta, sin embargo, que la producción oral se caracteriza por contradecir las convenciones sintácticas de la lengua escrita (Hidalgo Navarro y Pérez Giménez, 2004; 223-227): a pesar de que no se espere pausa que rompa la unidad de los componentes del sirrema, en el habla pueden en efecto producirse, debido a factores como interrupción o titubeo o a efectos voluntarios en la expresión como pueda ser el deseo de provocar expectación en el oyente (Navarro Tomás, 2004a: 31; Gili Gaya, 1988: 49-50; Quilis, 1999: 416-417; RAE y ASALE, 2011: 42), lo que en la versificación se refleja mediante el encabalgamiento, que consiste precisamente en separar los componentes de un mismo sirrema mediante pausa versal (Quilis, 1984: 81-82; Domínguez Caparrós, 2001: 129). En estos casos, la entonación, mediante el suspenso, cumple el papel de continuación sintáctica entre versos (Gili Gaya, 1993: 51).

En el estudio que nos ocupa, la correspondencia fisiológica y lingüística existente entre habla y verso, las distintas funciones del acento de intensidad y la ruptura de unidades sintagmáticas por medio de pausa inesperada tienen una relevancia fundamental, como veremos a continuación.

\section{6. "Lo fatal": versos 8 y 12}

Encontramos tres casos de encabalgamiento con alto valor expresivo ${ }^{11}$ en este poema, el primero de ellos en el verso 1, que cierra su primer hemistiquio con final oxítono, en la estructura conocida como alejandrino $a$ la francesa (Navarro Tomás, 1974: 423, 527; Torre, 1999: 83-87; Domínguez Caparrós, 2001: 31; Utrera, 2010: 229), dando lugar a una interrupción inesperada tras el fluido ritmo yámbico del primer hemistiquio, favorecido por la sinalefa entre que y es. Dado que la pausa suele impedir la sinalefa en la sílaba tónica que la precede (Navarro Tomás, 1974: 39 y 2004b: 16; Balbín, 1968: 74; Quilis, 1984: 52, 80; Domínguez Caparrós, 2001: 205 y 401), el empleo de sinalefa en este caso concreto parece inducir a que el receptor no anticipe la pausa, cuyo carácter inesperado puede evocar un efecto de titubeo, fortalecido por el encabalgamiento entre el verbo, que queda en el primer hemistiquio, y su atributo apenas sensitivo. Este encabalgamiento puede explicar la irregularidad métrica del verso 12, por lo que nos detenemos a observar su valor expresivo; Utrera (2010: 229) subraya la influencia simbolista en esta creación de expectativas mediante el encabalgamiento entre hemistiquios.

El segundo caso de encabalgamiento expresivo que se da en "Lo fatal" tiene lugar entre los versos 8 y 9 y ha llamado la atención de la práctica totalidad de sus estudiosos.

Lo primero que alerta al lector es que el verso finaliza con la preposición por, lo que lleva a una palabra átona a ocupar una posición prosódica clave en el verso: la del eje rítmico, que, como hemos recordado antes, necesariamente corresponde a palabras tónicas, o al menos así se observa en la tradición métrica española ${ }^{12}$; la presencia de una palabra átona en esta posición del verso, en opinión de Navarro Tomás (1974: 420-421), no altera la estructura métrica pero obliga a "cierta violencia de la espontaneidad fonética".

Se ha notado asimismo que este encabalgamiento se da, además, entre estrofas, acentuando la expectación (Morris, 1966: 470; Predmore, 1971: 435; Carranza Crespo, 1979: 147; Utrera Molina, 2016: 229), dado que cabe percibir mayor duración en la pausa entre estrofas que en las que se dan entre versos y entre hemistiquios (Navarro Tomás, 1974: 40; Balbín, 1968: 160, 166 y 168; Quilis, 1984: 79; Domínguez Caparrós, 2001: 259-260).

Como el acento final del verso, según hemos recordado al estudiar la correspondencia entre verso y grupo fónico, es el más prominente (Navarro Tomás, 2004b: 20, Balbín, 1968: 40-42; Quilis, 1984: 33, 95-96; Domínguez Caparrós, 2001: 17-18), se puede interpretar (y así se ha hecho en casos semejantes al análisis que nos ocupa, como vemos en Navarro Tomás, 1974: 420; en Balbín, 1968: 113-114; o en Domínguez Caparrós, 2001: 17-18) que recae sobre por el acento prosódico correspondiente al eje rítmico, lo que dotaría a la preposición de una tonicidad insólita e impropia del habla hispana: y por la sombra y PÓR.

Jakobson (1981: 369-370) describe una "expectación frustrada" en el receptor del verso cuando se altera el uso tradicional de los acentos. Nos encontramos ante uno de esos casos que, a juicio de Navarro Tomás (1974: 420-421), violentan la correspondencia entre sintaxis y verso, sin duda un ejemplo de los "no pocos

\footnotetext{
${ }^{11}$ Hay también encabalgamiento entre los hemistiquios del verso 7, pero se trata de un caso suave que casi pasa desapercibido, por lo que no le prestamos atención en este estudio.

${ }^{12}$ Martínez Fernández (2001) ofrece un ilustrativo estudio de excepciones a esta convención.
} 
problemas" métricos planteados por Rubén Darío a los que se refiere Domínguez Caparrós (1999: 47, 5657), quien señala dos soluciones posibles a casos de discrepancia entre ritmo y sintaxis como este: una consiste en ignorar el metro y seguir la prosodia normal de la lengua, mediante una "lectura prosaica" en la que se deshace el esquema del verso; otra, totalmente opuesta, en ignorar la prosodia y ajustarse al metro, mediante una "lectura musical" que desobedece a la realidad sintáctica de la lengua escrita ${ }^{13}$ y complica el entendimiento del contenido.

La segunda opción implica someter por completo el modelo de ejecución al modelo de verso; la primera, en cambio, supone un modelo de ejecución absolutamente ajeno al modelo de verso.

Es posible, sin embargo, una aproximación conciliadora entre la lectura musical y la prosódica, basada en lo expuesto anteriormente al atender a los diferentes tipos de acento de intensidad y fiel a pautas normales de habla que pueden seguir reflejándose en la versificación.

Como hemos ya referido, el mismo Navarro Tomás (2004a: 194-195) explica que el acento predominante de una frase, "reforzado por circunstancias lógicas o emocionales", puede estar tanto en posición final (caso normal del eje rítmico en un verso, según hemos visto hasta ahora) como en posición inicial o intermedia, "según la importancia relativa" de las palabras en el sentido de la frase. También Gili Gaya (1993: 50) comprueba, mediante análisis instrumental, que la relevancia de sentido de una palabra concreta con mayor valor de significado contrarresta la prominencia de otros acentos en relación con el tono.

De este modo, podemos asumir que la palabra más relevante o con mayor "importancia relativa" en el segundo hemistiquio del verso 8 es el sustantivo sombra, lo que eximiría a por de prominencia acentual, sin que por ello dejase de rimar con terror (verso 6). La prominencia tónica en el sustantivo sombra también destacaría este término en su oposición a vida, sustantivo que porta el acento de frase en el primer hemistiquio.

Junto con la pausa estrófica que le sigue, la atenuación acentual de por al final del verso 8 reforzaría el efecto de suspensión provocado por este caso de encabalgamiento que a su vez es tan característico de este poema. Ello permitiría que esa "expectación frustrada" a la que alude Jakobson cumpliera con una función expresiva de intensificación del suspenso, en lugar de provocar el efecto contrario de distorsión del habla que corre el riesgo de empobrecer el significado. Además, con ello se ajustaría a la normalidad prosódica de nuestra lengua. La declamación de este hemistiquio con prominencia tónica en el sustantivo en lugar de la preposición y con pausa larga estrófica volvería por tanto a conectar el poema con la naturalidad de la lengua hablada, en la que se da cabida al suspenso mediante interrupción inesperada del discurso, como hemos visto en el apartado sobre correspondencias entre verso y habla.

Siguiendo también las observaciones fonéticas de Navarro Tomás (2004a: 195) acerca del acento rítmico que se percibe en sílabas débiles en una concatenación de cierta extensión de sílabas, entendemos que, por la extensión silábica del hemistiquio, la preposición por, en las dos ocasiones en que se pronuncia en este hemistiquio, recibe este aumento de intensidad que en otro trabajo (Navarro Tomás, 2004b: 18-20) denomina apoyo secundario e ilustra que el ritmo frecuentemente se sirve de él en la versificación española. En el caso del segundo hemistiquio del verso 8, este apoyo o acento secundario (Domínguez Caparrós, 2001: 21-22) favorece el ritmo yámbico (y POR la SOMbra y POR) presente también en otros hemistiquios del poema. Esta tonicidad puramente rítmica, secundaria, en las preposiciones, estudiada por el propio Navarro Tomás, no plantea ningún conflicto con las pautas normales de habla.

Dada la conexión lingüística entre verso y grupo fónico, que históricamente se ha reflejado en la vinculación didáctica de métrica y dicción, no parece imposible que, si el habla admite flexibilidad acentual como para que, en ocasiones, el acento enfático sea más prominente que el acento de frase, el verso admita también esta excepción expresiva.

En cualquier caso, se ha destacado la habilidad de Rubén Darío en el uso del encabalgamiento, que en este caso concreto que tenemos entre manos hace ganar significado al poema (Urrutia, 1973: 864). También, que a diferencia de otras ocasiones anteriores en que Darío ha terminado versos con esta preposición en encabalgamiento, nunca adquiere expresividad tan extraordinaria como en "Lo fatal" (Urrutia, 1973: 867) ${ }^{14}$.

\footnotetext{
${ }^{13}$ Recuérdese que la sintaxis oral frecuentemente se aleja de la escrita (Hidalgo Navarro y Pérez Giménez, 2004), según hemos visto antes.

${ }^{14}$ Coke-Enguidanos (1985) estudia el empleo de encabalgamiento por Quevedo como recurso de expresión existencial en composiciones de dicho carácter, concluyendo que constituye un precedente del existencialismo del siglo XX. Identifica además la etimología de existencia, en el sentido de sobresalir espacialmente, con el encabalgamiento, encontrando con ello correspondencia formal y lingüística entre el tema y el recurso.
} 
Creemos que esa expresividad se corresponde mejor con el modelo de ejecución del acento enfático en el sustantivo sombra que con una lectura rítmica que deposite intensidad anómala en la preposición por, en un extremo, o una lectura prosódica que ponga en riesgo el efecto del encabalgamiento, según alerta Domínguez Caparrós (1988: 253-254), en el otro.

Por otro lado, este modelo de ejecución se ajusta a la correspondencia entre metro y significado, que, como hemos visto en el apartado 2, no han de separarse (Torre, 1999: 20).

Para finalizar este apartado de nuestro estudio, centramos ahora la atención en el verso 12, en el que entendemos que se da un tercer caso de encabalgamiento con efecto expresivo, sobre el que no hemos logrado encontrar datos en las fuentes consultadas. La razón que nos lleva a entender su presencia es fundamentalmente métrica, por lo que nos disponemos a explicar a continuación una escansión que no parece haber sido tenida en cuenta y que resultaría en potenciación expresiva del tema desarrollado en la composición, lo que nos hace pensar que pudiera haber sido la escansión planeada por el autor, aunque no pasa de ser una hipótesis. En cualquier caso, nos apoyamos en la observación de Domínguez Caparrós (1999: 52) de que el análisis métrico de los versos darianos "dista de ser una actividad mecánica de recuento de sílabas".

Amado Alonso (1969: 329-330) considera que la expresión de angustia existencial en este poema llega a su paroxismo en el verso 12, que define como eneasílabo conformado por cuatro pies "yámbicos fuertes" que viola el esquema alejandrino mantenido en los once versos anteriores; este esquema métrico predominante en el poema retornaría a su cauce en el verso final, heptasílabo, coincidente con la cantidad silábica de cada hemistiquio del verso alejandrino. Para Alonso (1969: 328), este descuido de la "perfección retórica del ritmo" habitual en las composiciones de Darío no perjudica en absoluto el caso particular de este poema.

Predmore (1971: 436) también entiende que una estructura eneasílaba rompe el patrón métrico en el verso 12, al igual que Domínguez Caparrós (1999: 62) también computa este verso como eneasílabo. Cupo (1968, cit. en Binns, 1998a: 300) ve simplemente que el esquema alejandrino del poema se trastoca en el final con la adición de dos versos libres. Cabe señalar a este respecto la observación de Domínguez Caparrós (1999: 50) sobre la complejidad métrica en ciertos versos de Rubén Darío, que el lector actual puede confundir con versos libres, caso que podría darse en este: sostenemos que el verso 12 no es ni verso libre ni eneasílabo, sino métricamente complejo; que mantiene, a la misma vez que altera, el esquema alejandrino predominante. Entendemos que se trata de un verso compuesto cuyo segundo hemistiquio se ha truncado, presentando un tercer encabalgamiento en el poema, esta vez entre partícula interrogativa y verbo. Marcamos a continuación la pausa entre hemistiquios que da lugar al encabalgamiento:

\section{2 iy no saber adónde | vamos}

El primer argumento que nos lleva a plantear esta escansión del verso 12 de "Lo fatal" es la inercia rítmica generada en los once versos precedentes, que han impuesto un esquema estable de pausa entre hemistiquios. La lógica visual de la disposición gráfica del poema empuja a ver el verso 12 como eneasílabo, como hiciera Amado Alonso, pero creemos que en una composición dariana habría de pesar más la lógica rítmica, verbal, inherente al verso, que la imagen sobre el papel.

Ciertamente este verso cumple la función culminante de la expresión de la angustia y la incertidumbre que señaló Amado Alonso, y la lleva a cabo mediante el factor inesperado de la ruptura y el suspenso sugeridos por su alteración métrica; pero parecería quizá más propio de la minuciosa conciencia creadora de Rubén Darío que dicha alteración, que realza el sentimiento de fatalidad construido a lo largo de los versos precedentes y adelanta el final abrupto que efectúa el verso siguiente, tuviera lugar no en un metro ajeno a la composición, sino en el segundo hemistiquio de un verso alejandrino como los demás, que de este modo queda incompleto como la vida misma ante la llegada inoportuna de su final.

El encabalgamiento provocado por la pausa enfatizaría así la pregunta existencial, el desconocimiento último de lo que aguarda al ser humano después de la existencia. Cerraría también un esquema de encabalgamientos expresivos al sumarse al del primer verso y al del octavo, conformando un empleo simétrico del recurso: entre hemistiquios en la parte inicial del poema, entre versos y estrofas en la parte central, y de nuevo entre hemistiquios en la parte final. Se destacarían por tanto las ideas de dichosa insensibilidad del árbol, en primer lugar, de sufrimiento por nuestra ignorancia, en segundo, y de angustia ante la incógnita final, por último.

El ritmo yámbico, por su parte, identificaría el contenido del hemistiquio y no saber adónde con el de los hemistiquios pues no hay dolor más grande (verso 3), y ser sin rumbo cierto (verso 5), de estar mañana muerto (verso 7), y por la sombra y por (verso 8) y y apenas sospechamos (verso 9), dejando estos seis 
hemistiquios en contraposición al contenido de los cuatro hemistiquios de los versos 1 y 2 , que con el mismo ritmo describen la placidez del árbol y la piedra.

Presentamos a continuación los versos analizados añadiendo marcas de suspenso entonativo en los casos de encabalgamiento, así como los acentos de verso en sus sílabas correspondientes, según el modelo de análisis que sigue el manual de análisis de textos poéticos de López-Pasarín (2016: 199-200 y 349), distinguiendo acento primario (') y apoyo secundario (') según explica Navarro Tomás (2004b: 18-20), y separamos las sílabas métricas en cada hemistiquio mediante punto elevado $(\cdot)$ :

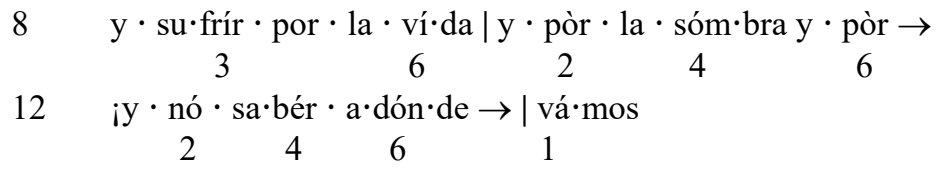

La carga expresiva de estos tres casos de encabalgamiento, que subrayan conceptos clave en el desarrollo de la composición, y la escansión abrupta del verso 12, se asocian formalmente con la disposición estrófica del poema en la transmisión del mensaje.

\section{Estructura estrófica}

La composición, de trece versos con los ocho primeros estructurados en dos serventesios, a primera vista evoca la apariencia de un soneto cuyo final se ha precipitado o ha quedado interrumpido, careciendo del verso número catorce y quedando mutilados el doce $\mathrm{y}$ el trece, como previamente han notado otros estudiosos del poema ${ }^{15}$. Desde esta impresión, unos autores interpretan que de hecho es un soneto, tal como se constata en varios trabajos recientes ${ }^{16}$, mientras que Binns (1998a: 300-302; y 1998b: 226) contempla esta denominación con distancia y reservas, Amado Alonso (1969) no parece observar esta posibilidad y otros analistas como Morris (1966), Predmore (1971) y Carranza Crespo (1979) no atienden a esta particularidad métrica.

Llama la atención que Tomás Navarro Tomás (1974), en su riguroso inventario de metros y estrofas empleados en la poesía en español, no mencione la composición que nos ocupa en ninguna de las páginas dedicadas al modernismo, al soneto en general, o a ninguna otra combinación estrófica en particular. Tampoco los trabajos aquí consultados de Balbín, Quilis ni Domínguez Caparrós hacen referencia en modo alguno a la circunstancia estrófica de este poema, aunque Quilis (1984: 140-141) nombra expresamente a Rubén Darío al poner un ejemplo de soneto en alejandrinos y sin la estructura de rima convencional.

Contamos con el precedente dariano del "Soneto de trece versos", antes mencionado, que Domínguez Caparrós define como "soneto sin el último verso"; Navarro Tomás especifica que se trata de ese poema concreto, así titulado, de la tercera sección (Otros poemas) de Cantos de vida y esperanza, en metro eneasílabo, en el que se omite el verso catorce, "perdido en la vaguedad del recuerdo", para crear suspenso. Añade que existen referencias a un precedente literario, improbablemente tenido en cuenta por Darío en opinión de Navarro Tomás: un soneto de trece versos, pero este con sentido completo, de Calderón de la Barca (Navarro Tomás, 1974: 432).

El hecho de que en el mismo poemario que culmina con "Lo fatal" se encuentre un soneto de trece versos, así denominado por el mismo Darío, cuyo final obedece al propósito de dejar en suspenso el poema, resulta, cuando menos, significativo para nuestro estudio. Igualmente significativo resulta el hecho de que la composición XI de la primera sección del mismo libro ("Mientras tenéis, oh negros corazones..."), aunque en endecasílabos, presente la misma estructura que "Lo fatal": trece versos con el esquema de rima ABAB CDCD EFEEF, lo que presenta no solamente tres casos de aparente soneto al que se ha amputado el último verso, sino también dos casos de estructura idéntica en cuanto a distribución de la rima.

\footnotetext{
${ }^{15}$ Niall Binns (1998a: 300) se remonta a Carlos Óscar Cupo (de quien cita: ““Lo fatal” lleva la distribución de un soneto en alejandrinos que resulta incompleto porque Rubén sustituye el terceto final por dos versos libres") y a Keith Ellis ("disruption of the sonnet in what might have been the final tercet").

${ }^{16}$ Valgan como ejemplo las siguientes citas de Cervera Salinas (1996: 105): “el famoso soneto "Lo fatal” de Rubén Darío"; López Martínez (2013: 40): "Rubén Darío en el famoso final del soneto "Lo fatal"”; Sancholuz (2016: 54): "el famoso soneto "Lo fatal"”; y el título mismo de Gámez Millán (2016): ““'Lo fatal” de Rubén Darío: ¿el soneto filosófico más bello de nuestra lengua?”
} 
Por otro lado, la rápida mirada histórica que hemos efectuado en el apartado correspondiente a los usos de composición de sonetos en nuestra lengua ilustra que, si bien se impuso la convención de estructurar las rimas de los primeros ocho versos en el esquema ABBA ABBA, previamente el Marqués de Santillana había empleado esquemas de rima variopintos y en el modernismo se vuelven a ampliar las combinaciones de rimas, al igual que los metros empleados (Navarro Tomás, 1974: 155-156, 400-401 y 468). Existen de hecho denominaciones específicas como soneto terciado, para el que comienza con serventesios en lugar de cuartetos ( $\mathrm{ABAB} \mathrm{ABAB})$; soneto de cuartetos independientes, para el que posee rimas distintas entre las dos primeras estrofas (como en el caso de los serventesios de "Lo fatal": ABAB CDCD); soneto polimétrico, para el que presenta versos de distinta cantidad silábica, como sucede por ejemplo en el soneto doblado anteriormente referido, que además cuenta con veinte versos en lugar de catorce (Domínguez Caparrós, 2001: 412-414, 418-419, 421).

Aunque para Binns (1998a: 300-301) sea precisamente la irregular disposición de las rimas en "Lo fatal" un argumento de peso contrario a que se trate de un soneto, dado que Rubén Darío, según Binns (pero recuérdese el ejemplo mencionado por Quilis, 1984: 140-141), no habría practicado esta variedad de rimas en sus sonetos anteriores, no vemos que ello suponga impedimento alguno para considerar el caso de esta composición como el de un soneto, así como tampoco su número de versos, teniendo además en cuenta que no sería el primero de trece, interrumpido en su final por efecto expresivo, compuesto por Rubén Darío.

Después de haber roto con el molde tradicional del soneto en lo que respecta al número de versos en su "Soneto de trece versos" y en la composición XI de Cantos de vida y esperanza, en la que también experimenta en lo referente a estructura de la rima, no sería extraño que Rubén Darío se decidiese a continuar explorando estas rupturas ya puestas en práctica.

Si considerásemos la idea de un modelo de estrofa que, al igual que el modelo de verso con las formas posibles de un verso concreto, abarcase las diferentes realizaciones posibles del soneto, desde las estructuras de rima inusuales hasta el empleo de versos de arte menor o versos compuestos o la alternancia de metros e incluso la adición o sustracción de versos, siempre que se mantuviera la unidad temática y de sentido que caracterizan al soneto en el plano del contenido, podría tal vez entenderse la posibilidad de denominar soneto a esta composición.

\section{Métrica y oralidad en "Lo fatal"}

El acertado empleo del encabalgamiento en los versos 1 (con sinalefa en acento final de hemistiquio) y 8 (con empleo de acento enfático que resta prominencia al eje rítmico de ese verso) y las posibles rupturas con el molde convencional del alejandrino, por un lado, mediante la singularidad métrica del verso 12, y con el del soneto, por otro, mediante la quiebra o mutilación de sus últimos versos, otorgan a esta pieza clave de la producción de Rubén Darío rasgos miméticos de la espontaneidad oral.

Se ha señalado que, en la trayectoria poética de Rubén Darío, Cantos de vida y esperanza presenta sus más audaces innovaciones en el ritmo, manejando la sorpresa y la fluidez hasta una "comunicación perfecta entre el lenguaje escrito y el hablado" (Corrales Arias, 2006: 74). También, que en la poesía de Darío hay un trasfondo recurrente de fuga o de metamorfosis, de deseo de transformación, de identificación de lo estático con toda suerte de prisión y del movimiento con la libertad (Aguado-Andreut, 1960: 47). En este sentido, conviene recordar que el verso, aunque es una estructura, no constituye un producto rígido sino un modelo de ejecución abierto a interpretaciones rítmicas (Domínguez Caparrós, 1988: 245).

A este respecto, resulta oportunamente ilustrativo un trabajo de Navarro Tomás (1944) que trata específicamente de la pronunciación de Rubén Darío, en el que se destaca la observancia de la ortología por parte del poeta, su naturalidad y suavidad en la dicción, su íntimo sentido del ritmo y, en sus últimos años, etapa en la que podemos ubicar la composición de "Lo fatal", un "cansancio que se reflejaba en el tono e inflexiones de su voz" (Navarro Tomás, 1944: 1).

La representación de pautas prosódicas del habla en el verso es una constante en la obra de Rubén Darío, según Navarro Tomás (1944: 8), lo que lleva al ilustre filólogo a identificar la interiorización del ritmo como mayor influencia de su pronunciación en sus versos, en los que así refleja su dominio técnico del habla. Esto, sin embargo, se contradice con la percepción de "violencia de la espontaneidad fonética" que el mismo Navarro Tomás (1974: 421) expresa al respecto de las innovaciones modernistas en el ejercicio del alejandrino; posición que podría entenderse, en el caso de los versos que hemos analizado en este estudio, si la dicción se aferrase al extremo de una lectura musical, ajustada al modelo de verso. Sin embargo, las observaciones de Navarro Tomás sobre la pronunciación de Rubén Darío apuntan a una mayor posibilidad de la solución intermedia, entre musical y prosódica, del modelo de ejecución que hemos considerado. 
Domínguez Caparrós (1988: 256) opina que la solución de problemas métricos como la disparidad entre modelo de verso y modelo de ejecución pasaría por analizar la ejecución de los versos por sus propios autores. En el caso que nos ocupa, dicha solución es imposible; pero de acuerdo con lo expresado por Navarro Tomás (1944) y el resto de autoridades (tanto en estudios del habla como del verso) en los trabajos aquí consultados, confiamos en que la escansión de los versos 8 y 12 que hemos planteado podría corresponderse con el sentido general y completo diseñado por Rubén Darío, que, efectivamente, lograría en esta composición un magnífico equilibrio entre el carácter íntimamente humano del contenido y los rasgos de espontaneidad oral de la forma.

\section{Referencias bibliográficas}

Aguado-Andreut, Salvador (1960), "En el mundo poético de Rubén Darío: huir, volar... ser otra cosa”, Hispanófila 10, págs. 47-56.

Alarcos Llorach, Emilio (2004), "Poesía y estratos de la lengua", en M. L. Burguera Nadal (ed.). Textos clásicos de teoría de la literatura. Madrid: Cátedra, págs. 331-336.

Alatorre, Antonio (2001), “Avatares del verso alejandrino”, Nueva Revista de Filología Hispánica XLIX.2, págs. 363407.

Alcina Franch, Juan y José Manuel Blecua Perdices (1975). Gramática española. Barcelona: Ariel.

Alonso, Amado (1969). Materia y forma en poesía. Madrid: Gredos.

Balbín, Rafael de (1968). Sistema de rítmica castellana. Madrid: Gredos.

Bello, Andrés (1835). Principios de ortología y métrica de la lengua castellana. Santiago de Chile: Imprenta La Opinión.

Benítes, Rubén (1972), "Schopenhauer en "Lo fatal” de Rubén Darío", Revista Iberoamericana 80, págs. 507-512.

Benot, Eduardo (1892). Prosodia castellana y versificación. Madrid: Casa Editorial Juan Muñoz.

Blanco, Emilio (1995), "Para las fuentes de Rubén Darío (con una nota sobre "Lo fatal")", Anales de Literatura Hispanoamericana 24, págs. 145-157.

Binns, Niall (1998a), "Poesía al borde del abismo: "Lo fatal" de Rubén Darío", en Cristóbal Cuevas y Enrique Baena (eds.). Rubén Darío y el arte de la prosa: ensayo, retratos y alegorías. Málaga: Universidad de Málaga, págs. 293302.

(1998b), "Entre la historia literaria y la poesía: vigencia y anacronismo de Rubén Darío", en Alfonso García Morales (ed.). Rubén Darío. Estudios en el centenario de Los raros y Prosas profanas. Sevilla: Universidad de Sevilla, págs. 217-240.

Caramuel Lobkowitz, Juan (2007). Primer Cálamo. Tomo II: Rítmica. Edc. de Isabel Paraíso. Valladolid: Universidad de Valladolid.

Carranza Crespo, Raquel (1979), "Un análisis de "Lo fatal” de Rubén Darío", Nueva Revista de Filología Hispánica 28.1, págs. 136-151.

Cervera Salinas, Vicente (1996). La palabra en el espejo: estudios de literatura hispanoamericana comparada. Murcia: Universidad de Murcia.

Coke-Enguidanos, Mervyn (1985), "Enjambment in Quevedo's Poetry: An Existencial Device and Other Uses", Hispania 68.3, págs. 452-460.

Corrales Arias, Adriano (2006), “Asedios musicales a la revolución poética de Rubén Darío", Revista Comunicación 15.1, págs. 70-74.

Díaz Rengifo, Juan (2007). Arte poética española. Valladolid: Maxtor.

Domínguez Caparros, José (1988), “Los conceptos de modelo y ejemplo de verso, y de ejecución”, Epos 4, págs. 241258.

(1999). Estudios de métrica. Madrid: UNED.

(2001). Diccionario de métrica española. Madrid: Alianza.

Gámez Millán, Sebastián (2016), “'Lo fatal' de Rubén Darío: ¿el soneto filosófico más bello de nuestra lengua?”, Sur 8. Disponible en: http://www.sur-revista-de-literatura.com/Paginas08/04Lofatal.pdf

Gil Fernández, Juana (2007). Fonética para profesores de español: de la teoría a la práctica. Madrid: Arco Libros.

Gili Gaya, Samuel (1988). Elementos de fonética general. Madrid: Gredos. (1993), "La entonación en el ritmo del verso", en Isabel Paraíso Almansa (ed.). Samuel Gili Gaya: Estudios sobre el ritmo. Madrid: Istmo, págs. 43-52.

Gutiérrez Carou, Javier (1992), "Métrica y rima en los sonetos del Marqués de Santillana", Revista de Literatura Medieval IV, págs. 123-144.

Henríquez Ureña, Pedro (1998) "En busca del verso puro", en J. L. Abellán y A. M. Barrenechea (eds.). Pedro Henríquez Ureña: Ensayos. Madrid: ALLCA XX, págs. 154-173.

López Martínez, M M Isabel (2013), "Neruda, lector de literatura norteamericana", RILCE 24.1, págs. 36-56.

Hidalgo Navarro, Antonio y Montserrat Pérez Giménez (2004), "De la sintaxis a la pragmasintaxis: problemas del análisis sintáctico en el discurso oral espontáneo", Cauce 27, págs. 221-245. 
Hidalgo Navarro, Antonio y Mercedes Quilis Merín (2012). La voz del lenguaje: fonética y fonología del español. Valencia: Tirant Humanidades.

Hualde, José Ignacio (2005). The Sounds of Spanish. Nueva York: Cambridge University Press.

López-Pasarín Basabe, Alfredo (2016). Teoría y práctica del análisis de textos poéticos. Madrid: Devenir.

MapesS, E. K. (1940), “Innovación e influencia francesa en la métrica de Rubén Darío”, Revista Hispánica Moderna 6.1, págs. 1-16.

Martínez Fernández, José Enrique (2001), “Final de verso en partícula átona (tradición e innovación métrica en la poesía de Antonio Carvajal)", Signa 10, págs. 295-312.

Morris, Anne Maria (1966), “'Lo fatal’ de Rubén Darío”, Grial 4.14, págs. 470-474.

Navarro Tomás, Tomás (1944) "La pronunciación de Rubén Darío”, Revista Hispánica Moderna 10.1-2, págs. 1-8.

------------, ------ (1974). Métrica Española. Reseña histórica y descriptiva. 5a ed. Madrid: Guadarrama. (2004 $)$. Manual de pronunciación española. $28^{\mathrm{a}}$ ed. Madrid: CSIC.

(2004b). Arte del verso. Madrid: Visor.

Nebrija, Antonio (1980) Gramática de la lengua castellana. Ed. de Antonio Quilis. Madrid: Editora Nacional.

Paraíaso Almansa, Isabel (2000). La métrica española en su contexto románico. Madrid: Arco Libros.

Predmore, Michael (1971), "A Stylistic Analysis of "Lo fatal””, Hispanic Review 39.4, págs. 433-438.

Prieto, Pilar (2007), "Phonological Phrasing in Spanish", en S. Colina y F. Martínez Gil (eds.). Optimality-Theoretic Advances in Spanish Philology. Ámsterdam: John Benjamins, págs. 39-60.

Quilis, Antonio (1984). Métrica española. Barcelona: Ariel. (1999). Tratado de fonología y fonética españolas. Madrid: Gredos.

Real Academia Española y Asociación de Academias de la Lengua Española (2011) Nueva gramática de la lengua española. Fonética y fonología. Barcelona: Espasa.

Rico, Francisco (1985), "La clerecía del mester”, Hispanic Review 53.1, págs. 1-23.

Sancholuz, Carolina (2016) "Poesía y movimiento: figuraciones de la errancia en Rubén Darío", CHUY Revista de estudios literarios latinoamericanos 3, págs. 48-56.

Sicilia, Mariano José (1832). Lecciones elementales de ortología y prosodia. Madrid: Imprenta Real.

Torre, Esteban (1999). El ritmo del verso. Murcia: Universidad de Murcia.

------, ------- (2013), “Zeuxis y azeuxis. Más sobre vocales en contacto”, Rhythmica XI, págs. 187-205.

Torre, Guillermo (1966). Antología poética. Buenos Aires: Losada.

Uría Maqua, Isabel (1986), "Gonzalo de Berceo y el Mester de Clerecía en la nueva perspectiva de la crítica", Berceo 110-111, págs. 7-20.

Urrutia, Jorge (1973), "Primera aproximación a un uso dariano (notas para una teoría del encabalgamiento)", Anales de Literatura Hispanoamericana 2-3, págs. 859-870.

Utrera Molina, M ${ }^{\mathrm{a}}$ Victoria (2016), "Ecos del simbolismo en la métrica modernista: el verso alejandrino", Rhytmica VIII, págs. 219-234. 